\title{
The Modification of Polyurethane Foams Using New Boroorganic Polyols: Obtaining of Polyols with the Use of Hydroxypropyl Urea Derivatives
}

\author{
Iwona Zarzyka \\ Department of Organic Chemistry, Faculty of Chemistry, Rzeszow University of Technology, Al. Powstancow Warszawy 6, \\ 35-959 Rzeszow, Poland \\ Correspondence should be addressed to Iwona Zarzyka; izarzyka@prz.edu.pl
}

Received 22 January 2014; Revised 5 March 2014; Accepted 8 March 2014; Published 27 April 2014

Academic Editor: Yulin Deng

Copyright (C) 2014 Iwona Zarzyka. This is an open access article distributed under the Creative Commons Attribution License, which permits unrestricted use, distribution, and reproduction in any medium, provided the original work is properly cited.

\begin{abstract}
Methods of synthesis of new prospective polyol components for obtaining of polyurethane foams of reduced combustibility using eco-friendly substrates have been presented. With this end in view, $\mathrm{N}, \mathrm{N}^{\prime}$-bis(2-hydroxypropyl)urea was esterified with boric acid and next the hydrogenborate obtained was hydroxyalkylated by the excess of propylene carbonate. The influence of the way of esterification on the hydroxypropyl derivatives of borate substituted urea properties has been investigated. Esterification was run in the presence and in the absence of solvent. According to instrumental analysis, the characteristic of hydrogenborates obtained in both methods was found to be similar. The hydroxypropyl derivatives of borate substituted urea show similar spectral characteristics and thermal stabilities and differ slightly in molar masses, by-product contents, and physical properties, particularly viscosities. The properties of these derivatives were assessed paying special attention to their application as the polyol components of polyurethane foams. Hydroxypropyl urea derivatives, modified by boric acid, show changes in physical properties with temperature, similarly to typical polyols used for obtaining of polyurethane foams.
\end{abstract}

\section{Introduction}

Mass production of polyurethane materials results in increase of the requirements for production technology of these plastics and their properties. Special emphasis is put on environment-friendly activities nowadays. Exclusion of toxic and dangerous substances from natural environment is becoming a very important aspect of these actions [1]. The desired effect of these modifications is the improvement of output properties of the raw materials processed with no deterioration of the final product properties. The properties of foams can be controlled by chemical or physical modification of foam structures $[2,3]$.

The fundamental materials for the production of polyurethanes are isocyanates and active hydrogen-containing compounds, that is, polyols. Isocyanates react both with active hydrogen-containing compounds and, given the right conditions, with each other. Therefore in case of foamed mixtures containing unreacted isocyanate, side reactions are possible. Newly formed isocyanuric structures can significantly decrease flammability of polyurethane foams produced $[4,5]$. Instead of using excess of isocyanate, suitable (i.e., nitrogen-, boron-, or phosphorus-containing) polyols may be used to decrease flammability $[5,6]$.

This work concentrates on the synthesis of new polyols from eco-friendly substrates [7-12], containing active hydrogen atoms together with nitrogen and boron atoms. It is suspected that these polyols will decrease flammability of rigid polyurethane foams.

\section{Materials and Methods}

\subsection{Syntheses}

2.1.1. Reactions of $N, N^{\prime}$-Bis(2-hydroxypropyl)urea with Boric Acid-Synthesis EBUI. In a round bottom flask $6.6 \mathrm{~g}(0.0375$ moles) $\mathrm{N}, \mathrm{N}^{\prime}$-bis(2-hydroxypropyl)urea (BHPU) and $4.7 \mathrm{~g}$ (0.075 moles) boric acid (BA, pure, $\mathrm{POCH}$, Poland) were placed. The reaction mixture was stirred mechanically at 110 
$130^{\circ} \mathrm{C}$. The progress of reaction was monitored by determination of weight loss and acid number (AN) of reaction mixture.

\subsubsection{Reactions of EBUI with an Excess of Propylene Car-} bonate. In a $250 \mathrm{~cm}^{3}$ three-necked round bottom flask $10 \mathrm{~g}$ (0.0375 moles) BHPU esterified with boric acid (EBUI) and the appropriate amount of propylene carbonate (PC, pure, Fluka, Switzerland) were placed to reach the molar ratio of reagents of $1: 6,1: 12$, or $1: 18$ and $0.46-0.78 \mathrm{~g}$ potassium carbonate (12.0-20.8 g/mole EBU, 0.09-0.15 mole/mole $\mathrm{EBU}$ ) or $0.38-0.63 \mathrm{~g}$ diazabicyclo[2.2.2] octane (DABCO, 10.1-16.8 g/mole EBU, 0.09-0.15 mole/mole EBU) was added. The reaction mixture was stirred mechanically at 160 or $180^{\circ} \mathrm{C}$ with monitoring of reaction progress by determination of unreacted PC [13].

2.1.3. Reactions of BHPU with Boric Acid-Synthesis EBUII. $17.6 \mathrm{~g}$ ( 0.1 moles) of BHPU, $12.4 \mathrm{~g}$ ( 0.2 moles) of BA, and $100 \mathrm{~cm}^{3}$ of xylene were inserted into a round-bottomed flask that fits with mechanical stirrer, Dean-Stark trap, and reflux-condenser. Then it was heated to about $100^{\circ} \mathrm{C}$ and set stable until 0.2 moles of water was azeotropically distilled. The xylene was distilled off in a rotary evaporator and the reaction's product (EBUII) was dried off to a stable weight in a vacuum dryer at $90^{\circ} \mathrm{C}$ and $0.09 \mathrm{MPa}$.

\subsubsection{Reactions of EBUII with an Excess of Propylene Car-} bonate. In a $250 \mathrm{~cm}^{3}$ three-necked round bottom flask $10 \mathrm{~g}$ (0.0375 moles) EBUII and the appropriate amount of propylene carbonate (PC, pure, Fluka, Switzerland) were placed to reach the molar ratio of reagents of $1: 6,1: 12$, or $1: 18$ and $0.62 \mathrm{~g}$ potassium carbonate $(16.6 \mathrm{~g} / \mathrm{mole}$ EBU, 0.12 mole/mole EBU) was added. The reaction mixture was stirred mechanically at $180^{\circ} \mathrm{C}$ with monitoring of reaction progress by determination of unreacted PC [13].

2.2. Analytical Methods. The product's molar masses [number-average $\left(\bar{M}_{n}\right)$, weight-average $\left(\bar{M}_{w}\right)$, and $z$-average $\left(\bar{M}_{z}\right)$ ] were determined with the use of a gel chromatograph Viscotec T60A equipped with RI detector (of refractive index). Separation was performed by means of two independent columns: PSS SDV (of $7.8 \mathrm{~mm} \times$ $300 \mathrm{~mm}$ dimensions), accompanied by TSK deposits of 100 and $1000 \AA$ pore diameter and the following recording conditions: $25 \pm 0,1^{\circ} \mathrm{C}$, eluent flow rate: $1 \mathrm{~cm}^{3} / \mathrm{min}$, injected sample size: $20 \mu \mathrm{dm}^{3}$, polymer concentration in solution: $5 \mathrm{mg} / \mathrm{cm}^{3}$, analysis time: $30 \mathrm{~min}$, and eluent: THF (distilled from above sodium); calibration was performed on the basis of typical polystyrene and branched references.

The elemental analysis $(\mathrm{C}, \mathrm{H}, \mathrm{N})$ of EBUI and II was made by means of an element analyzer Vario EL III C, H, N, S, and $\mathrm{O}$, manufactured by Elementar.

Boron content tests in products were performed by means of spectrophotometric method [14].

${ }^{1} \mathrm{H}$ - and ${ }^{11}$-B-NMR spectra of products were recorded with $500 \mathrm{MHz}$ spectrometer (Bruker, Germany) in $\mathrm{d}_{6}$-DMSO and HMDS or boron trifluoride reference. IR spectra were taken for films with ALPHA FT-IR spectrophotometer (Bruker).

MALDI ToF spectra of reaction products of urea with EC were obtained on BRUKER Autoflex Speed (Bruker Daltonik, Germany) mass spectrometer working at linear mode with delayed ion extraction, equipped with nitrogen laser working at $337 \mathrm{~nm}$. There was used method of laser desorption from the matrix, which was a plate of silver nanoparticles (AgNPET) [15]. The samples were diluted with methanol to $10 \mathrm{mg} / \mathrm{cm}^{3}$. Therefore in some cases the molecular ion weights were increased by the mass of $\mathrm{Ag}^{+}, \mathrm{H}^{+}, \mathrm{K}^{+}$(because of catalyst), and $\mathrm{CH}_{3} \mathrm{OH}$.

Chromatographic analysis of by-products, that is, propylene glycol (PG) and products of its consecutive reactions with PC (dipropylene glycols and tripropylene glycols), was performed with gas chromatograph Agilent Technologies 7890 A GC with FID detector. Initial temperature was $50^{\circ} \mathrm{C}$, heating rate $20^{\circ} \mathrm{C} / \mathrm{min}$, end temperature $220^{\circ} \mathrm{C}$, time of heating at $220^{\circ} \mathrm{C} 6 \mathrm{~min}$, loader temperature $250^{\circ} \mathrm{C}$, and detector temperature $300^{\circ} \mathrm{C}$. The samples were dissolved in methanol $(0.01 \mathrm{M})$. Internal reference was cyclohexanone. Percentage of glycols was calculated according to calibration curves.

Thermal analyses (DTG and TG) of products were performed in aluminum crucible, in temperature range of 20$600^{\circ} \mathrm{C}$, on approximately $2 \mathrm{mg}$ sample, under a nitrogen atmosphere with Termowaga TGA/DSC 1 derivatograph, Mettler.

The following properties of hydroxyethoxy derivatives of urea have been determined: pycnometer density, refractive index (with Abbe's refractometer), Höppler viscosity, and surface tension by ring detach method. All measurements were made in temperature range $20-80^{\circ} \mathrm{C}$.

\section{Results and Discussion}

To modify hydroxypropyl urea derivatives with boron it was decided to esterify $\mathrm{N}, \mathrm{N}^{\prime}$-bis(2-hydroxypropyl)urea (BHPU) with boric acid. See Figure 8.

Esterification was run in two ways. In the first method BHPU was directly esterified by boric acid (BA) in the absence of solvent, at the temperature range $110-130^{\circ} \mathrm{C}$. At the temperature above $130^{\circ} \mathrm{C}$ BA releases some water and turns into metaboric acid, whereas decreasing temperature below $110^{\circ} \mathrm{C}$ results in some problems with homogenization of reacting substances and considerable increases in reaction time.

The course of the reaction of BHPU with boric acid was followed based on mass balance (the water being released during reaction was evaporated) and acid number (AN) determination. The AN of the output mixture (assuming that boric acid acts as a monobasic acid during titration) should amount to $374 \mathrm{mg} \mathrm{KOH} / \mathrm{g}$, whereas, after 20 minutes, which is the time that is necessary for homogenization of reacting substances, the $\mathrm{AN}$ equals $17.4 \mathrm{mg} \mathrm{KOH} / \mathrm{g}$. At $130^{\circ} \mathrm{C}$ already after 45 minutes of reaction, the AN amounted to 0 and the mass balance did not indicate the end of the reaction yet. 
TABLE 1: Elemental analysis of the reaction mixture obtained at initial molar ratio of BHPU : BA $1: 2$ at temperature $110^{\circ} \mathrm{C}$.

\begin{tabular}{|c|c|c|c|c|c|c|c|c|}
\hline \multirow{2}{*}{ Time (h) } & \multicolumn{2}{|c|}{$\% \mathrm{~N}$} & \multicolumn{2}{|c|}{$\% \mathrm{C}$} & \multicolumn{2}{|c|}{$\% \mathrm{H}$} & \multicolumn{2}{|c|}{$\%$ B } \\
\hline & Calcd & Found & Calcd & Found & Calcd & Found & Calcd & Found \\
\hline 0 & 9.33 & 9.57 & 28.00 & $\% \mathrm{~N}$ & $\% \mathrm{~N}$ & 7.17 & - & - \\
\hline 6 & 10.61 & 10.42 & 31.82 & 31.69 & 6.82 & 6.90 & 8.20 & 8.37 \\
\hline 7 & 10.61 & 11.08 & 31.82 & 33.74 & 6.82 & 6.58 & - & - \\
\hline
\end{tabular}

The zero value of the AN, or rather the impossibility of its determination, follows from the presence of basic 1aminopropan-2-ol, formed as a result of BHPU condensation, which also takes place under reaction conditions. See Figure 9.

The analysis of ${ }^{1} \mathrm{H}-\mathrm{NMR}$ spectra of the reaction mixture showed the presence of carbamate groups, which confirms the condensation reaction. Signals at $4.65 \mathrm{ppm}$ and $8.2 \mathrm{ppm}$ from protons of methine group linked to oxygen atom of carbamate group $-\mathrm{CH}-\mathrm{O}(\mathrm{CO})-\mathrm{NH}-$ and from nitrogenadjacent proton appear in the spectrum [16]. At the same time a band at $1735 \mathrm{~cm}^{-1}$ coming from valence vibrations of carbamate $\mathrm{C}=\mathrm{O}$ bond is observed in the IR spectra of the products.

The end of the process determined by the mass balance was not observed until 90 minutes of the reaction. Based on spectroscopic analysis, that is, by comparison of signal intensities at 3.65 and $4.65 \mathrm{ppm}$ from methyl protons, respectively, in 2-hydroxypropyl groups esterified with boric acid and in oxypropylene groups adjacent to carbamate group, it was estimated that at $130^{\circ} \mathrm{C}$ already after 20 minutes of reaction $5 \mathrm{~mol} \%$ undergoes condensation. After an hour ca. $23 \mathrm{~mol} \%$ is condensed and this value remains constant while the reaction continues. Due to condensation, the next reactions of BHPU with boric acid were carried out at the lower temperature. $\mathrm{AN}$ was found to be 0 at $120^{\circ} \mathrm{C}$ after 1 hour, at $115^{\circ} \mathrm{C}$ after two hours, and at the temperature $110^{\circ} \mathrm{C}$ after 7 hours of the reaction.

At 120 and $115^{\circ} \mathrm{C}$ the participation of BHPU in condensation reaction is, respectively, 21 and $15 \mathrm{~mol} \%$ and at $110^{\circ} \mathrm{C}$ it is $9 \mathrm{~mol} \%$ of BHPU. The participation of BHPU in condensation depends on the temperature and decreases when the temperature decreases. The temperature $110^{\circ} \mathrm{C}$ was deemed to be optimal for the reaction of BHPU with boric acid.

According to the balance, theoretically calculated quantity of water $(1.35 \mathrm{~g})$ evaporates after 6 hours of reaction (Figure 1) and then AN determined amounts ca. $3.7 \mathrm{mg} \mathrm{KOH} / \mathrm{g}$ (Figure 1).

Elemental analysis of the mixture after reaction at $110^{\circ} \mathrm{C}$ also confirms the termination of the process after 6 hours (Table 1).

In ${ }^{11} \mathrm{~B}$-NMR spectra of reaction mixture (Figure 2) the gradual decrease of the signal at $19.89 \mathrm{ppm}$, coming from boron present in free boric acid, is observed for 6 hours; from then on the intensity of this signal remains constant (Figures 2(c) and 2(d)).

Due to condensation of BHPU, in the second method, the reaction of BHPU with boric acid was run in the

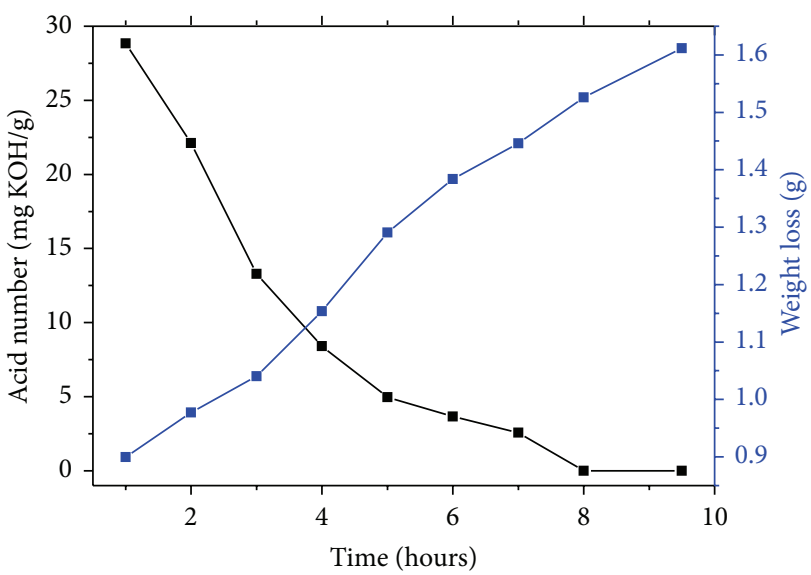

FIGURE 1: Weight loss and AN changes of BHPU and BA mixed at the molar ratio $1: 2$ during reaction at temperature $110^{\circ} \mathrm{C}$.

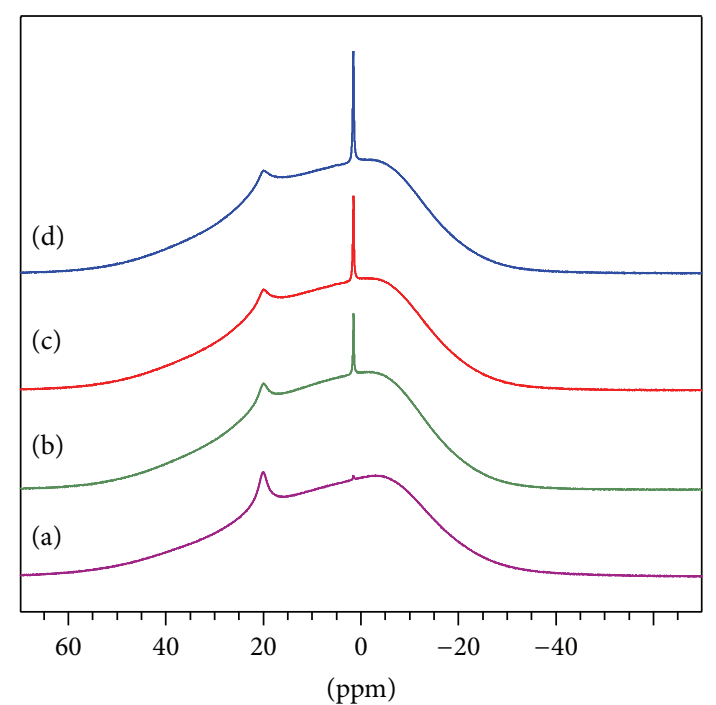

FIGURE 2: ${ }^{11} \mathrm{~B}-\mathrm{NMR}$ spectrum of reaction mixture obtained at the initial molar ratio of BHPU : BA $1: 2$ at temperature $110^{\circ} \mathrm{C}$ made after (a) homogenization of reagents, (b) 5, (c) 6, and (d) 7 hours of reaction.

presence of azeotropic solvent (xylene), with no catalyst. The participation of BHPU in condensation reaction decreased to $7 \mathrm{~mol} \%$.

The product obtained (EBUII) is a solid resin of pink color, and its composition was confirmed by elemental analysis $\left(\% \mathrm{~N}_{\text {calcd }}=10.61, \% \mathrm{~N}_{\text {found }}=10.68, \% \mathrm{C}_{\text {calcd }}=32.81\right.$, 


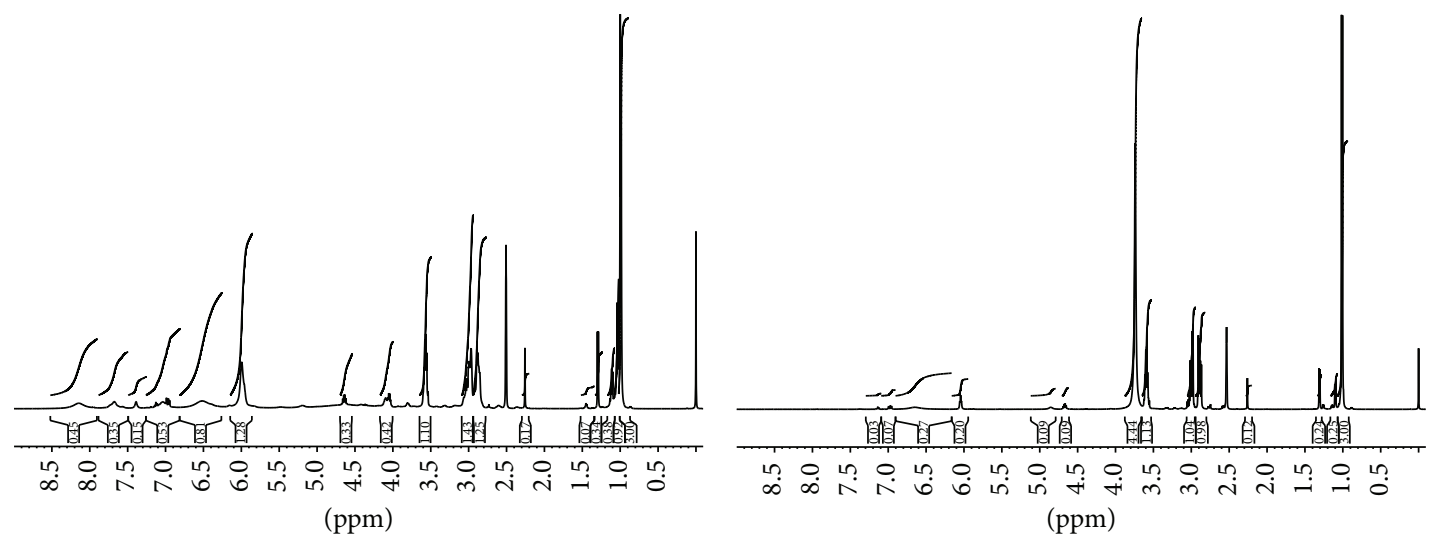

(a)

(b)

FIgURE 3: ${ }^{1} \mathrm{H}-\mathrm{NMR}$ spectrum of EBUII: (a) without $\mathrm{D}_{2} \mathrm{O}$ and (b) with $\mathrm{D}_{2} \mathrm{O}$ addition.

TABLE 2: Reaction conditions of EBUI and EBUII with PC.

\begin{tabular}{|c|c|c|c|c|c|c|}
\hline Synth. & Kind of EBU & $\begin{array}{l}\text { Initial molar } \\
\text { ratio of reagent }\end{array}$ & $\begin{array}{l}\text { Amount of } \mathrm{K}_{2} \mathrm{CO}_{3} \\
\text { (mole/BHPU mole) }\end{array}$ & Temp. $\left({ }^{\circ} \mathrm{C}\right)$ & $\begin{array}{l}\text { Reaction } \\
\text { time }(\mathrm{h})\end{array}$ & $\begin{array}{c}\text { Formal molar ratio } \\
\text { BHPU : oxypropylene unit in } \\
\text { product }\end{array}$ \\
\hline 1 & \multirow{7}{*}{ EBUI } & $1: 6$ & 0.09 & 160 & 30 & - \\
\hline 2 & & $1: 6$ & 0.15 & 160 & 26.5 & $1: 5.7$ \\
\hline 3 & & $1: 6$ & 0.09 & 180 & 9.75 & $1: 5.95$ \\
\hline 4 & & $1: 6$ & $0.09^{*}$ & 180 & 42 & $1: 5.0$ \\
\hline 5 & & $1: 6$ & $0.15^{*}$ & 180 & 34.5 & $1: 5.4$ \\
\hline 6 & & $1: 12$ & 0.12 & 180 & 14 & $1: 12.2$ \\
\hline 7 & & $1: 18$ & 0.12 & 180 & 22 & $1: 16.8$ \\
\hline 8 & \multirow{3}{*}{ EBUII } & $1: 6$ & 0.12 & 180 & 9.5 & $1: 3.8$ \\
\hline 9 & & $1: 12$ & 0.12 & 180 & 13 & $1: 9.6$ \\
\hline 10 & & $1: 18$ & 0.12 & 180 & 17.5 & $1: 15.2$ \\
\hline
\end{tabular}

${ }^{*} \mathrm{DABCO}$ was used as catalyst.

$\% \mathrm{C}_{\text {found }}=32.00, \% \mathrm{H}_{\text {calcd }}=6.82, \% \mathrm{H}_{\text {found }}=6.80, \% \mathrm{~B}_{\text {calcd }}=$ 8.0 , and $\% \mathrm{~B}_{\text {found }}=8.39$ ).

The ${ }^{1} \mathrm{H}$-NMR spectra of hydrogenborates for both methods are very similar. Signals at 2.90 and 3.00 ppm of methylene protons, of a chemical shift identical to the spectrum of BHPU alone, are observed (Figure 3). A signal of secondary amide protons undergoes a small shift from $5.95 \mathrm{ppm}$ to $6.05 \mathrm{ppm}$. In turn, signals from hydroxyl protons of hydrogenborate appear at chemical shift of $6.5-7.6 \mathrm{ppm}$. In IR spectrum of EBUII (Figure 4) a band at $1378 \mathrm{~cm}^{-1}$ coming from valence vibrations of borate $\mathrm{O}-\mathrm{B}$ bond is observed. The first and the second secondary amide band at 1635 and $1572 \mathrm{~cm}^{-1}$ are also recognizable.

\subsection{Reactions of $N, N^{\prime}$-Bis(2-hydroxypropyl)urea Hydrogenbo-} rate with Propylene Carbonate. Hydrogenborates obtained by method 1 (EBUI) and method 2 (EBUII) were subjected to hydroxyalkylation by the excess $\mathrm{PC}$ in the presence of potassium carbonate as a catalyst, at $160-180^{\circ} \mathrm{C}$ (Table 2 ). Reactions with EBUI were initially run at a temperature of $160^{\circ} \mathrm{C}$, the reaction time was long then, and the increase of

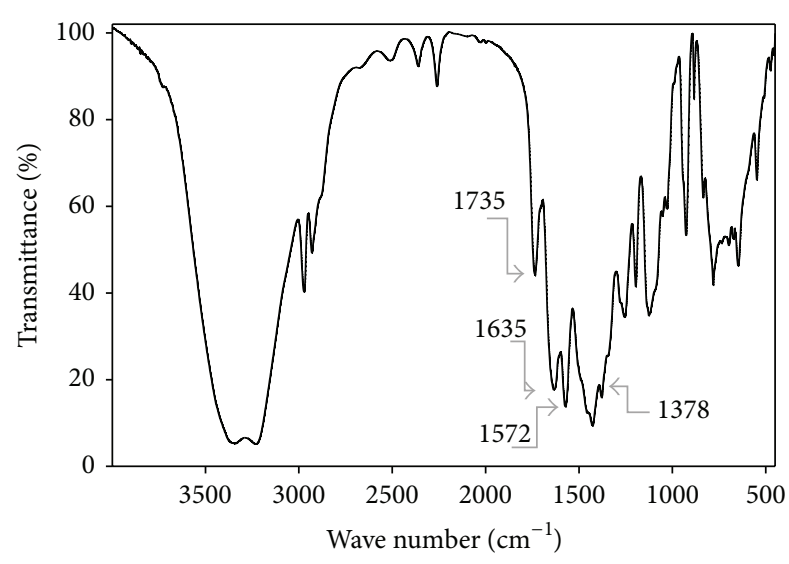

FIGURE 4: IR spectrum of EBUII.

the catalyst amount resulted in only little shortening of the process (Table 2, synth. 1 and 2). In turn, an increase of the reaction temperature to $180^{\circ} \mathrm{C}$ results in a threefold decrease in the reaction time (Table 2, synth. 1 and 3). Application of 


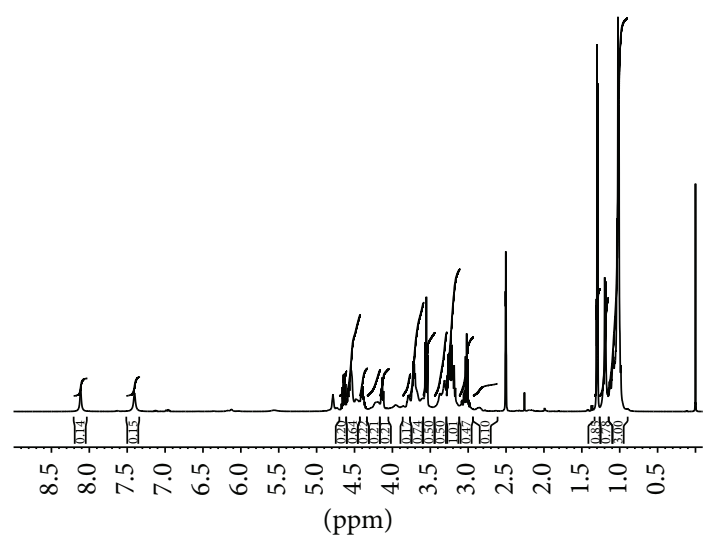

(a)

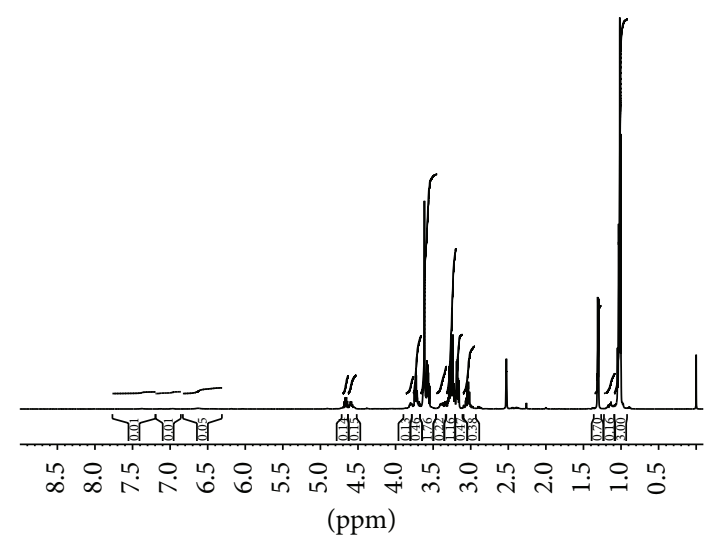

(b)

FIGURE 5: ${ }^{1} \mathrm{H}-\mathrm{NMR}$ spectrum of product obtained at the initial molar ratio of EBUII : PC $1: 6$ in the presence of $0.12 \mathrm{~mole}_{2} \mathrm{CO}_{3} / \mathrm{mole} \mathrm{EBU}$ at temperature $180^{\circ} \mathrm{C}$ : (a) without $\mathrm{D}_{2} \mathrm{O}$ and (b) with $\mathrm{D}_{2} \mathrm{O}$ addition.

DABCO as a catalyst not only decreases the reaction time but also limits the number of oxypropylene units preserved in the product structure (Table 2, synth. 2-5). Therefore $\mathrm{K}_{2} \mathrm{CO}_{3}$ was used for next syntheses and reactions were run at a temperature of $180^{\circ} \mathrm{C}$ (Table 2, synth. 6 and 7).

Reactions of hydrogenborate obtained according to method 2 (EBUII) with PC were carried out under the same conditions as used in the first reaction series with EBUI (Table 2, synth. 8-10). A spectroscopic analysis showed the analogous course of the reactions of EBUI and EBUII with PC. When carrying out an EBUI or EBUII reaction at 6-molar excess of PC, a product containing free hydroxyl groups of hydrogenborate and carbamic groups is formed, since signals at 7.4 and $8.2 \mathrm{ppm}$ are observed in ${ }^{1} \mathrm{H}$-NMR spectrum of the products (Figure 5(a)) that disappear after addition of $\mathrm{D}_{2} \mathrm{O}$ (Figure 5(b)).

In the products obtained at 6-molar excess of PC, free unreacted, secondary amide groups are not present already, as there is no signal at $6.0 \mathrm{ppm}$ (Figure 5(a)). In the IR spectrum of a product the second secondary amide band at $1540 \mathrm{~cm}^{-1}$ is not recognizable. However, the second tertiary amide band is observed at $1667 \mathrm{~cm}^{-1}$.

Moreover, in IR spectra bands at 1046,1090, and $1114 \mathrm{~cm}^{-1}$ occur, characteristic of valence vibrations of, respectively, primary and secondary alcohol $\mathrm{C}-\mathrm{OH}$ bonds and valence vibrations of $\mathrm{C}-\mathrm{O}-\mathrm{C}-$ in ethers. The presence of the latter band indicates that the consecutive reactions of hydroxyl of 2-hydroxypropyl group present in the derivative formed in the reaction with PC proceed more readily, compared with the reaction of hydrogenborate hydroxyl groups with PC. The band intensity increases according to the increase of PC excess used for the reaction. See Figure 10.

At 18-molar excess of PC in the IR spectrum of the product, only bands at 1114 and $1046 \mathrm{~cm}^{-1}$ are observed, which indicates the presence of ether bonds and primary hydroxyl groups.

In the ${ }^{1} \mathrm{H}-\mathrm{NMR}$ spectra of the products (Figure 5(b)) two signals were observed from protons of methine groups in the ester structure at 4.65 and $4.55 \mathrm{ppm}$. The former
TABLE 3: Boron percentage in obtained products.

\begin{tabular}{llccc}
\hline Entry* & Kind of EBU & $\begin{array}{c}\text { Initial molar ratio } \\
\text { of EBU : PC }\end{array}$ & \multicolumn{2}{c}{ \% boron $(\mathrm{wt} \%)$} \\
\hline 3 & \multirow{2}{*}{ EBUI } & $1: 6$ & 3.33 & 3.67 \\
6 & & $1: 12$ & 1.96 & 2.38 \\
\hline 8 & \multirow{2}{*}{ EBUII } & $1: 6$ & 3.28 & 3.57 \\
9 & & $1: 12$ & 2.03 & 2.43 \\
\hline
\end{tabular}

* Entry according to Table 2.

comes from carbamic groups, whereas the latter results from incorporation of carbonate groups into the structure of the product, according to Figure 11 in which $y \geq 0$.

Another confirmation of the presence of ester groups was provided by IR spectra of the products, in which the band at $1730 \mathrm{~cm}^{-1}$, characteristic of valence vibrations of the ester carbonyl group, is observed. At higher excess of $\mathrm{PC}$ in ${ }^{1} \mathrm{H}$ NMR spectra of the products only one signal is observed at $4.65 \mathrm{ppm}$ of methine protons adjacent to carbamic group.

The boron content in the products obtained in reactions with EBUI and EBUII and appropriate amounts of PC is similar and in agreement with the calculated one (Table 3).

The product mixture contains also by-productspoly(propylene glycols) (Table 4), formed in reaction of PC with water (propylene glycol (PG)) and in consecutive reactions of PG with PC. A total content of glycols in the products approaches $3.6 \mathrm{wt} \%$. The products are usually accompanied by DPGs; PG is not formed and TRIPGs are formed at 12-molar and higher excess of PC (Table 4).

Thermal analysis of the products of the reaction of EBU with PC showed the decrease of their thermal stability, compared to nonmodified by boron hydroxypropyl derivatives of urea [17]. On the DTG curve of the products of the reactions of EBUI and EBUII with 6-molar excess of PC, one peak with maximum at the temperature of, respectively, 205 and $215^{\circ} \mathrm{C}$ is observed. In the thermograms of the products obtained at higher excess of PC, two or three peaks occur 

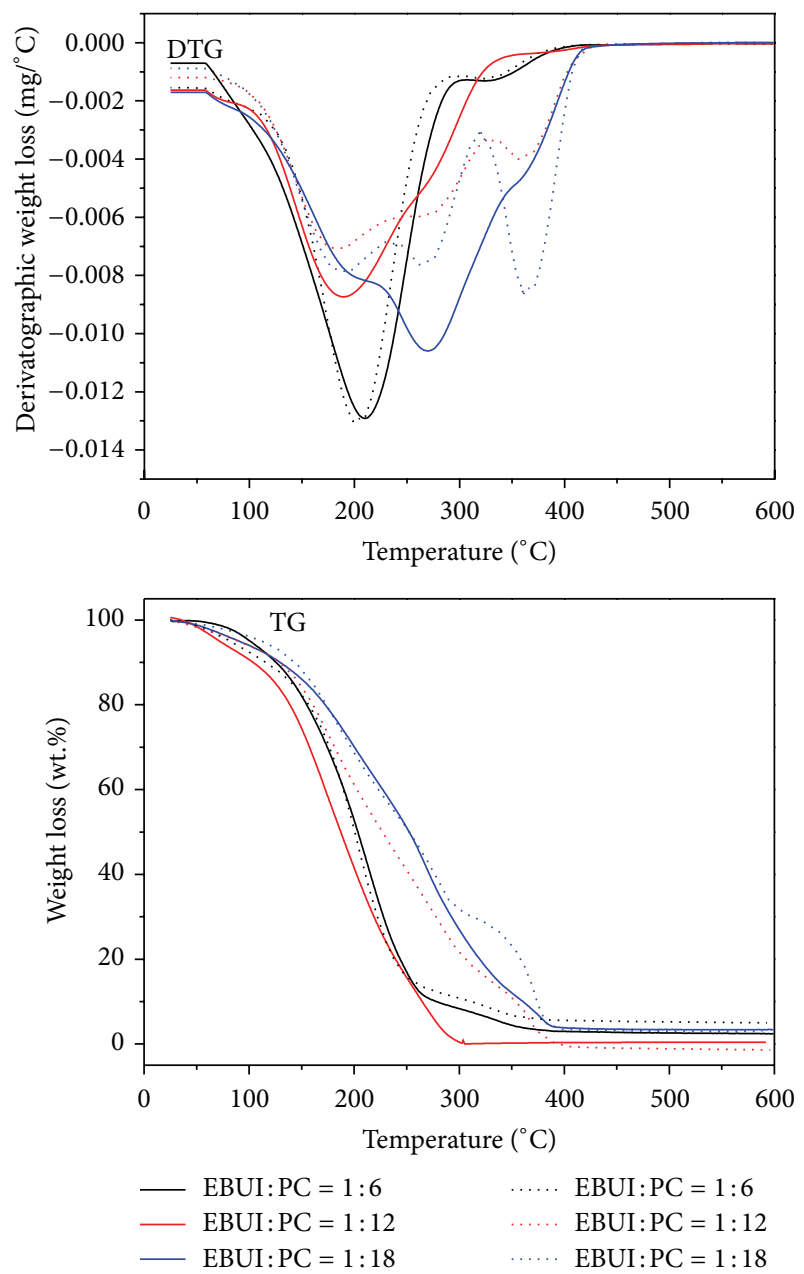

FIGURE 6: Thermogravimetry analysis of reaction products of EBUI and EBUII with excess of PC.

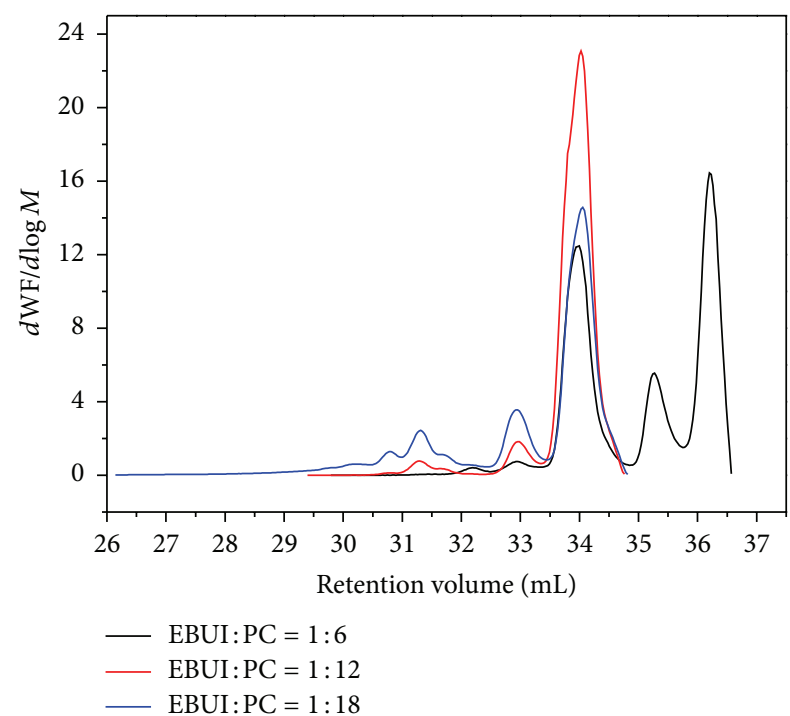

FIGURE 7: Molar mass distribution of the reaction products of EBUII with $\mathrm{PC}$ as a function of the retention volume.
TABLE 4: Percentage of by-products in reaction products of EBU with PC.

\begin{tabular}{lccc}
\hline Number $^{*}$ & \multicolumn{3}{c}{ Percentage of poly(propylene glycols) } \\
& DPG & TRIPG & $\sum$ \\
\hline 1 & 0.61 & 0 & 0.61 \\
2 & 3.44 & 0 & 3.44 \\
3 & 2.47 & 0 & 2.47 \\
4 & 3.59 & 0 & 3.59 \\
5 & 2.42 & 0 & 2.42 \\
6 & 0.92 & 0.74 & 1.68 \\
7 & 0.98 & 0.17 & 1.15 \\
8 & 0.88 & 0 & 0.88 \\
9 & 1.04 & 0.22 & 1.26 \\
10 & 0.98 & 0.93 & 1.91 \\
\hline
\end{tabular}

${ }^{*}$ Number according to Table 2.

TABLE 5: Thermal stability of reaction products of EBU with PC.

\begin{tabular}{lccccc}
\hline Number ${ }^{*} T_{5 \%}\left({ }^{\circ} \mathrm{C}\right)$ & $T_{10 \%}\left({ }^{\circ} \mathrm{C}\right)$ & $T_{20 \%}\left({ }^{\circ} \mathrm{C}\right)$ & $T_{50 \%}\left({ }^{\circ} \mathrm{C}\right)$ & $T_{\max }\left({ }^{\circ} \mathrm{C}\right)$ \\
\hline 3 & 135 & 150 & 175 & 215 & 205 \\
6 & 130 & 150 & 170 & 210 & 205 and 270 \\
7 & 135 & 155 & 190 & 265 & 205,280 and 370 \\
8 & 125 & 150 & 175 & 215 & 215 \\
9 & 130 & 150 & 180 & 240 & 205,270 and 370 \\
10 & 150 & 165 & 190 & 265 & 200,275 and 370 \\
* Number according to Table 2. $T_{X \%}$ : temperature, in which $X \%$ weight loss \\
occurs.
\end{tabular}

TABLE 6: Molar masses of the obtained polyols determined by means of GPC method.

\begin{tabular}{lcccc}
\hline Number & $\begin{array}{c}\bar{M}_{n} \\
(\mathrm{~g} / \mathrm{mole})\end{array}$ & $\begin{array}{c}\bar{M}_{w} \\
(\mathrm{~g} / \mathrm{mole})\end{array}$ & $\begin{array}{c}\bar{M}_{z} \\
(\mathrm{~g} / \mathrm{mole})\end{array}$ & $\begin{array}{c}\mathrm{HN} \\
(\mathrm{mg} \mathrm{KOH} / \mathrm{g})\end{array}$ \\
\hline 5 & 484 & 487 & 492 & $622 \pm 21$ \\
6 & 528 & 555 & 588 & $540 \pm 18$ \\
7 & 565 & 603 & 643 & $469 \pm 19$ \\
8 & 438 & 441 & 446 & $687 \pm 22$ \\
9 & 461 & 473 & 486 & $626 \pm 20$ \\
10 & 533 & 586 & 676 & $523 \pm 17$ \\
\hline
\end{tabular}

${ }^{*}$ Number according to Table 2.

at the temperature of $205,270-280$, and $370^{\circ} \mathrm{C}$ (Table 5, Figure 6). The first peak comes from the decomposition of borate groups [18], the second from the decomposition of carbonate and carbamate groups [13], and the third from the decomposition of urea groups [19].

The determined molar masses of the derivatives, obtained by GPC method (Table 6 and Figure 7), indicate that molar masses of the products increase according to the increase in PC excess used for the reaction. In Figure 7 an appearance of the subsequent fractions of higher mass, with the growth in PC excess used for polyol synthesis, is clearly visible. The molar masses are in the range of 441-586 and 487-603 g/mol for the products obtained in reactions with, respectively, 


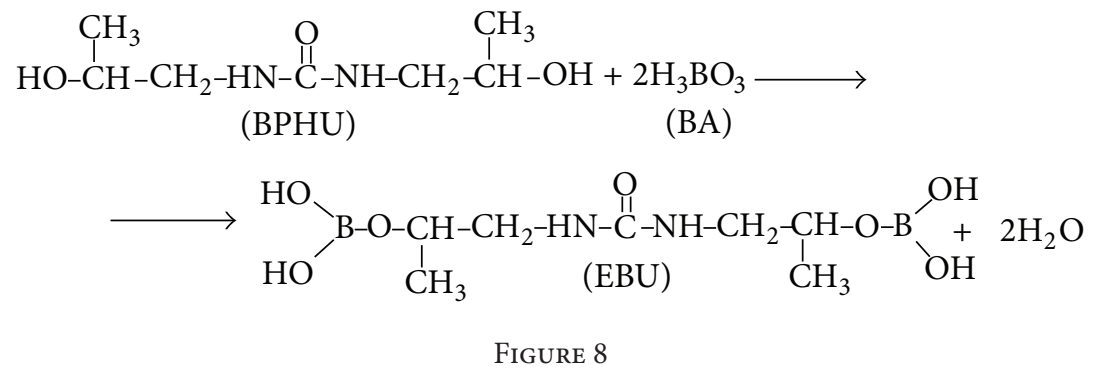

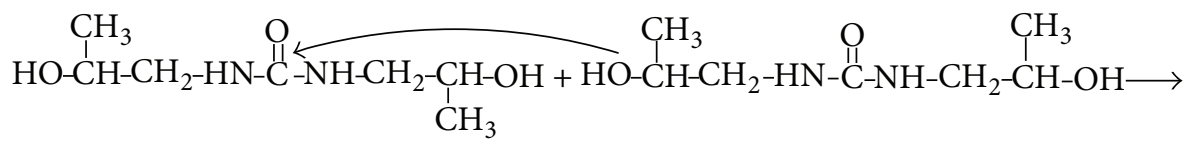

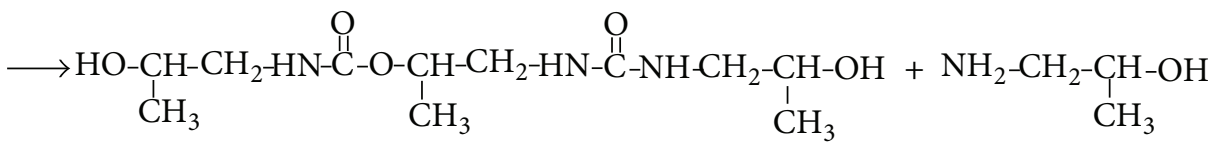

FiguRE 9

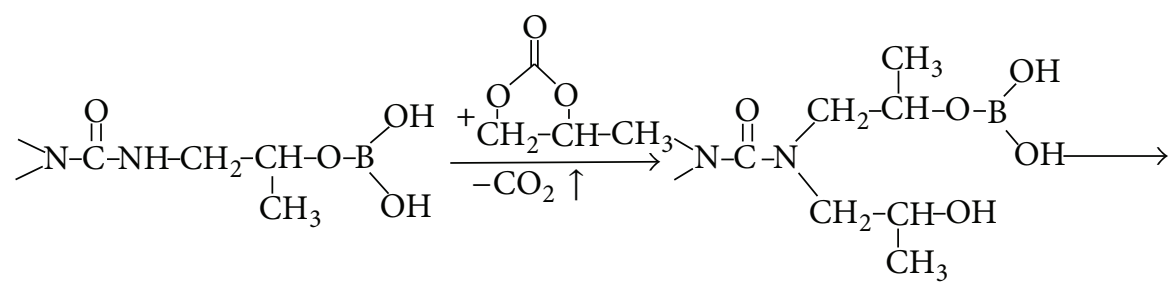

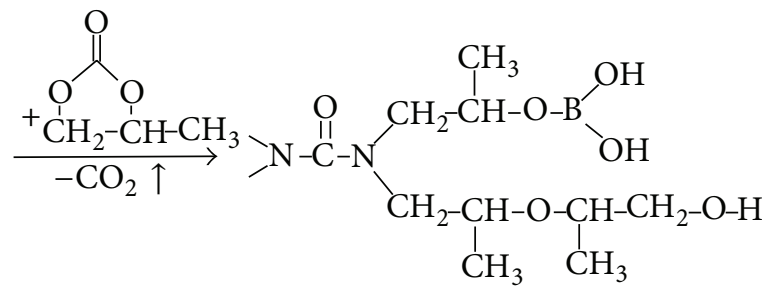

FIGURE 10

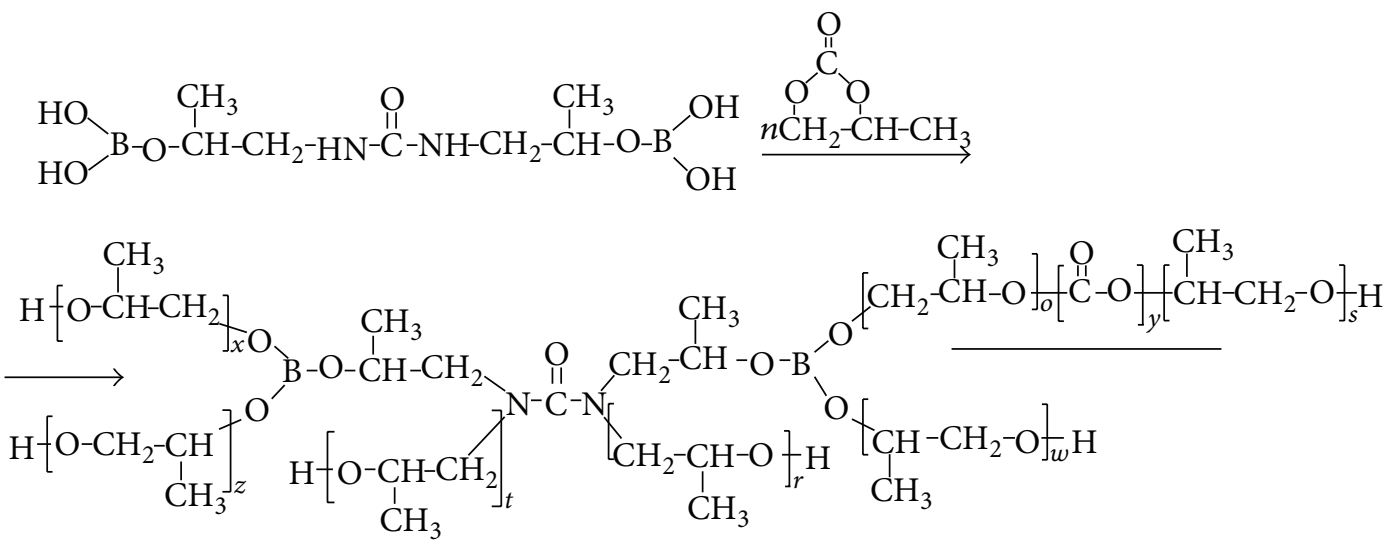

Figure 11 
TABLE 7: Physical properties of reaction products of EBU with PC measured at $20^{\circ} \mathrm{C}$.

\begin{tabular}{lccc}
\hline Type of derivative & $\begin{array}{c}\text { Density } \\
\left(\mathrm{cm}^{3} / \mathrm{g}\right)\end{array}$ & $\begin{array}{c}\text { Surface tension } \\
(\mathrm{N} / \mathrm{m})\end{array}$ & $\begin{array}{c}\text { Viscosity } \\
(\mathrm{Pa} \cdot \mathrm{s})\end{array}$ \\
\hline EBUI : PC $1: 6$ & 1.125 & 0.0336 & 1.369 \\
EBUI : PC $1: 12$ & 1.110 & 0.0355 & 1.001 \\
EBUI : PC $1: 18$ & 1.096 & 0.0375 & 0.584 \\
EBUII : PC $1: 6$ & 1.161 & 0.0353 & 5.212 \\
EBUII : PC $1: 12$ & 1.124 & 0.0354 & 3.211 \\
EBUII : PC $1: 18$ & 1.116 & 0.0433 & 2.841 \\
\hline
\end{tabular}

EBUI and EBUII (Table 6). The products obtained in the reactions with EBUI have slightly higher molar masses.

Maldi ToF analysis confirmed the presence of carbonate and carbamate groups in the product structure. The compositions of the product mixtures obtained at 6- and 12molar excess of PC/mol EBUI and EBUII are similar; the products represent a mixture of oligomers containing up to, respectively, 6 and 9 oxypropylene units per mole of oligomer. The differences in the composition are observed at 18-molar excess of PC; the oligomers contain up to, respectively, 11 moles of oxypropylene units per mole of EBUI and 9 moles of oxypropylene units per mole of EBUII.

The physical properties of the products obtained, such as density, viscosity, and surface tension, have been examined. It was observed that the physical properties of the products of reaction of EBU with excess of PC are influenced by the method of synthesis of EBU. Table 7, presenting the density, surface tension, and viscosity data at $20^{\circ} \mathrm{C}$, shows that higher values of the properties were measured for the products obtained using EBUII. Density and surface tension data are moderately close to each other; the greatest differences are observed for viscosity values. It was found that the change in these properties with temperature follows the same tendency as the change of physical properties of typical polyetherols, used for obtaining of polyurethane foams [20]. Density and surface tension change linearly whereas viscosity follows exponential dependence. These properties enable their application as prospective polyol components for obtaining of polyurethane foams.

\section{Recapitulation and Conclusions}

To modify the structures of hydroxypropyl urea derivatives with boron, $\mathrm{N}, \mathrm{N}^{\prime}$-bis(2-hydroxypropyl)urea was esterified with boric acid. Esterification was run in the presence and in the absence of solvent. According to instrumental analysis, the characteristic of hydrogenborates obtained in both methods was found to be similar. Hydrogenborates obtained in both methods were hydroxyalkylated by the excess of propylene carbonate in order to examine the influence of the synthesis method on the properties of the derivatives obtained. The hydroxypropyl derivatives of borate substituted urea show similar spectral characteristics and thermal stabilities and differ slightly in molar masses, by-product contents, and physical properties, particularly viscosities.
Hydroxypropoxyl urea derivatives, modified by boric acid, show changes in physical properties with temperature, similarly to typical polyols used for obtaining of polyurethane foams.

Obtaining of foamed polyurethane materials using the synthesized derivatives and investigation of properties of the foams, paying special attention to the influence of the boron introduction on the foam properties, will be the subject of a separate paper.

\section{Disclosure}

NMR spectra were recorded within U-264/DS.

\section{Conflict of Interests}

The author declares that there is no conflict of interests regarding the publication of this paper.

\section{References}

[1] K. Hill, "Fats and oils as oleochemical raw materials," Pure and Applied Chemistry, vol. 72, no. 7, pp. 1255-1264, 2000.

[2] S. Lu and I. Hamerton, "Recent developments in the chemistry of halogen-free flame retardant polymers," Progress in Polymer Science, vol. 27, no. 8, pp. 1661-1712, 2002.

[3] M. Hirschler, in NFPA Fire Protection Handbook, chapter 3, section 6, NFPA, Quincy, Mass, USA, 20th edition, 2008.

[4] J. L. Rivera-Armenta, T. Heinze, and A. M. Mendoza-Martínez, "New polyurethane foams modified with cellulose derivatives," European Polymer Journal, vol. 40, no. 12, pp. 2803-2812, 2004.

[5] O. Kwon, S. Yang, D. Kim, and J. Park, "Characterization of polyurethane foam prepared by using starch as polyol," Journal of Applied Polymer Science, vol. 103, no. 3, pp. 1544-1553, 2007.

[6] R. E. Myers, E. D. Dickens Jr., E. Licursi, and R. E. Evans, "Ammonium pentaborate: an intumescent flame retardant for thermoplastic polyurethanes," Journal of Fire Sciences, vol. 3, no. 6, pp. 432-449, 1985.

[7] "Boric acid exhibits very low toxicity by primary skin Irritation, low toxicity by acute oral and inhalation, moderate toxicity by dermal and high toxicity by primary eye irritation," http://www.epa.gov/oppfead1/labeling/lrm/chap-07.pdf.

[8] Boric Acid/Sodium Borate Salts: HED Chapter of the Tolerance Reassessment Elegibility Decision Document (TRED), U.S. Environmental Protection Agency, Office of Prevention, Pesticides, and Toxic Substances, Health Effects Division, U.S Government Printing Offices, Washington, DC, USA, 2006.

[9] WHO, Environmental Health Criteria 204: Boron, International Programme on Chemical Safety, World Health Organization, Geneva, Switzerland, 1998.

[10] http://www.huntsman.com/portal/page/portal/performance products/Media\%20Library/a MC348531CFA3EA9A2E040EBCD2B6B7B06/Products_ MC348531D0B9FA9A2E040EBCD2B6B7B06/Carbonates_ MC348531D1109A9A2E040EBCD2B6B7B06/files/jeffsol_ alkylene_carbonates_in_industrial_cleaner_formulations.pdf.

[11] K. Grice, H. Sattar, and H. Baker, "Urea and retinoic acid in ichthyosis and their effect on transepidermal water loss and water holding capacity of stratum corneum," Acta DermatoVenereologica, vol. 53, no. 2, pp. 114-118, 1973. 
[12] R. H. Jacoby and J. J. H. Gilkes, "A new urea/hydrocortisone powder cream compared with other topical corticosteroid preparations: a six centre study," Current Medical Research and Opinion, vol. 2, no. 8, pp. 474-481, 1974.

[13] M. Kucharski and D. Kijowska, "Synthesis of polyetherols from melamine and propylene carbonate. II," Journal of Applied Polymer Science, vol. 89, no. 1, pp. 104-115, 2003.

[14] Polish (European) Standards: PN-EN, 13346:2002.

[15] J. Niziol, W. Rode, B. Laskowska, and T. Ruman, "Novel monoisotopic ${ }^{109}$ AgNPET for laser desorption/Ionization mass spectrometry," Analytical Chemistry, vol. 85, no. 3, pp. 19261931, 2013.

[16] Ch. Pauchert and J. Behnke, The Aldrich Library of ${ }^{13} \mathrm{C}$ and $1 \mathrm{H}$ NMR Spectra, vol. 1, uk, 2nd edition, 1993.

[17] V. Nedel'ko, Y. Mikhailov, N. Chukanov, V. Saldin, L. Ganina, and V. Buznik, "The thermal decomposition of hexamethylenetetraammonium dodecahydro-closo-dodecaborate," Russian Journal of Physical Chemistry B, vol. 5, no. 1, pp. 26-32, 2011.

[18] H. A. Reed, C. E. White, V. Rao, S. A. B. Allen, C. L. Henderson, and P. A. Kohl, "Fabrication of microchannels using polycarbonates as sacrificial materials," Journal of Micromechanics and Microengineering, vol. 11, no. 6, pp. 733-737, 2001.

[19] W. H. Awad and C. A. Wilkie, "Investigation of the thermal degradation of polyurea: the effect of ammonium polyphosphate and expandable graphite," Polymer, vol. 51, no. 11, pp. 2277-2285, 2010.

[20] Z. Wirpsza, Polyurethanes: Chemistry, Technology, Applications, Wydawnictwa Naukowo-Techniczne, Warsaw, Poland, 5th edition, 1991. 

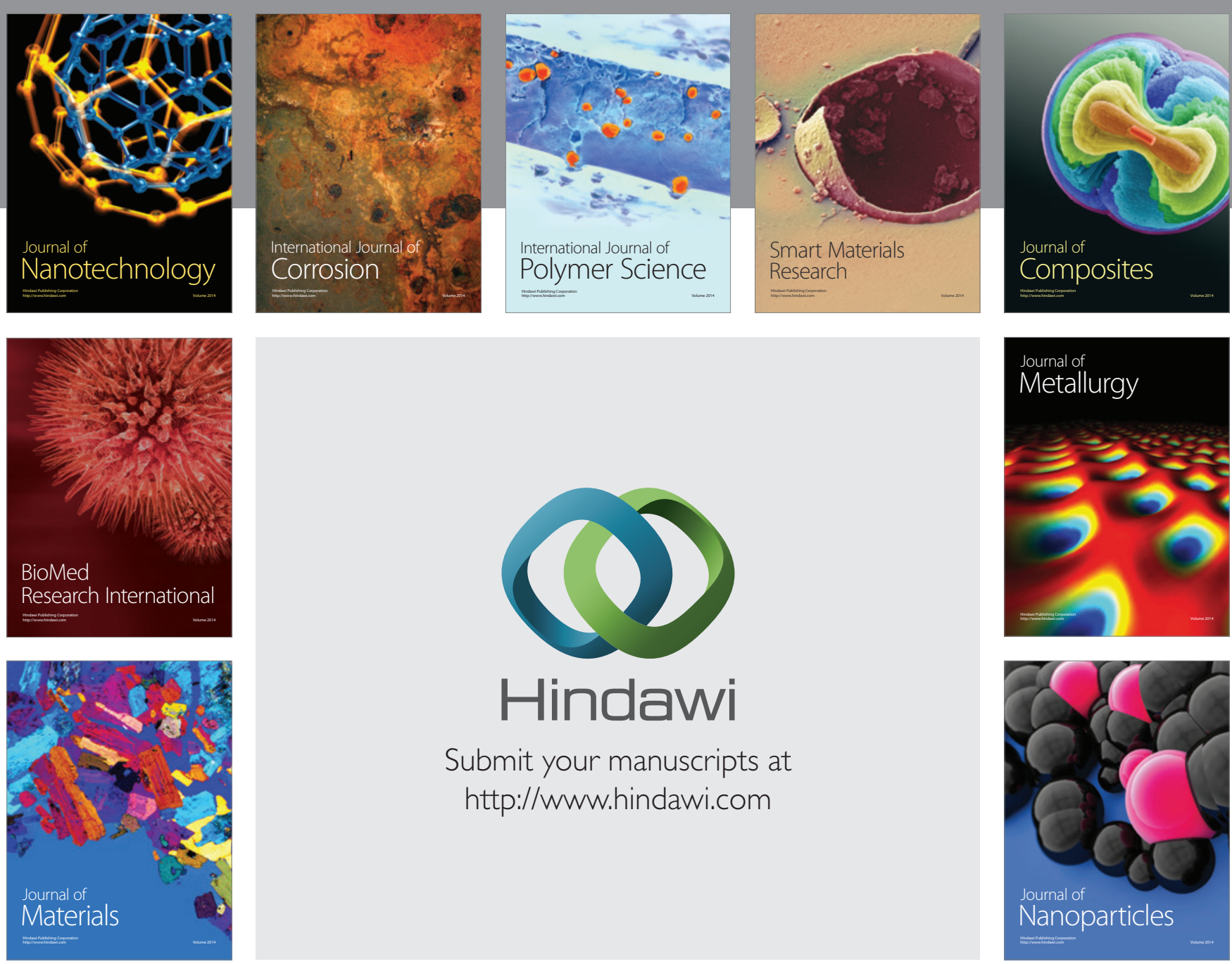

Submit your manuscripts at http://www.hindawi.com
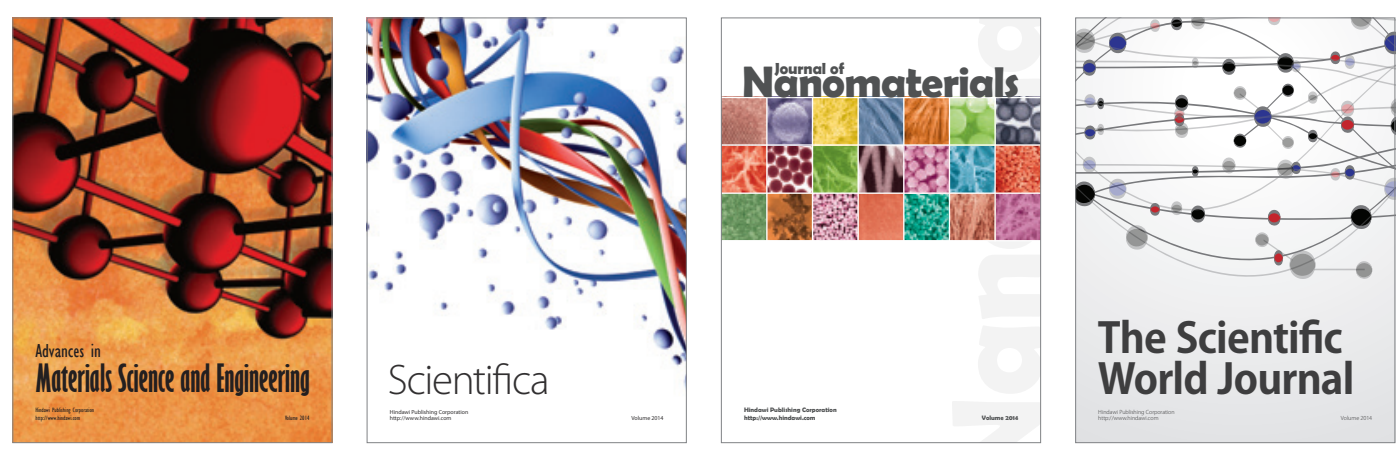

\section{The Scientific World Journal}
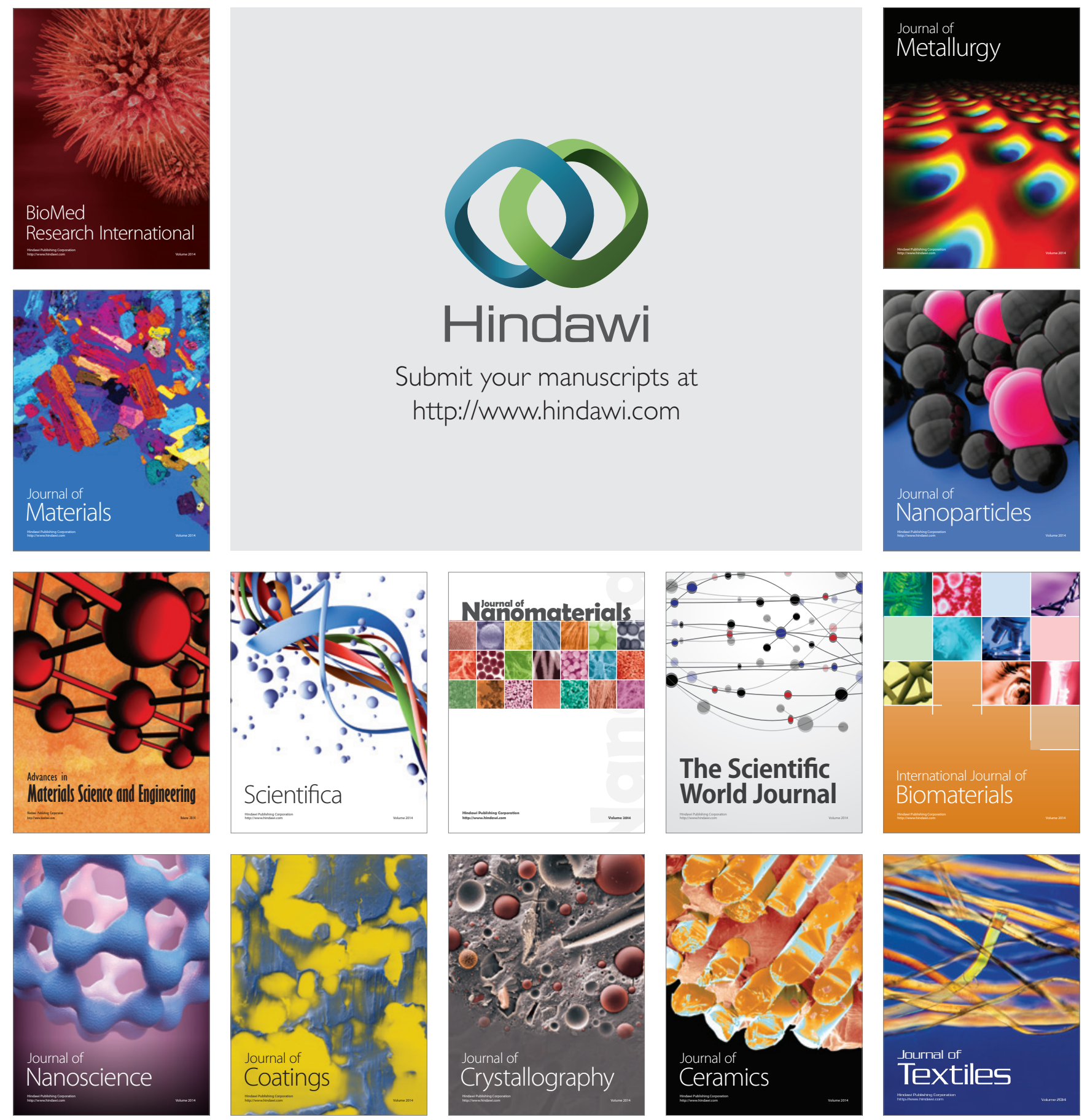